\title{
Molecular Techniques in the Diagnosis and Management of Infectious Diseases: Do They Have a Role in Bacteriology?
}

\author{
Ian R. Poxton
}

Division of Medical Microbiology, Centre for Infectious Diseases, University of Edinburgh College of Medicine and Veterinary Medicine, Edinburgh, UK

\section{Key Words}

Diagnostic methods, traditional versus molecular techniques - Resistance to antimicrobial agents • Koch's postulates

\begin{abstract}
The diagnosis and management of bacterial diseases has been done by traditional methods for a century or more. With the advent of molecular methods, however, these traditional approaches are being challenged. This review examines the pros and cons of traditional versus modern methods and tries to answer the question: when are molecular methods useful or essential? The following topics are addressed with appropriate examples: diagnosis; identification, typing and fingerprinting; pathogenesis; patient management; susceptibility to disease, and resistance to antimicrobial agents. It was concluded that there is still a place for both traditional and modern molecular methods, and training of staff must include both methodologies. Innovation is encouraged - but new technologies must be thoroughly tested before introduction into the routine lab. Liaison between laboratory scientist and physician is important, but above all experience is paramount.
\end{abstract}

\section{Introduction}

In microbiology, a commonly held view is that virologists have to use molecular techniques to diagnose and manage disease, yet bacteriologists do not need to use them as bacteria can be easily cultured and identified. After all, traditional means have been used for over a hundred years. However, is this view really true in the 21 st century?

The advantages of traditional culture methods are obvious in that they show the 'whole picture', they are quantitative, isolates can be typed or fingerprinted (by phenotypic or genotypic methods), antibiotic sensitivity tests can be done, isolates can be archived and the methods have stood the test of time. The disadvantages are that they are slow, require skilled, experienced personnel and only cultivable bacteria can be detected, which is not possible if the culture medium does not support their growth or if antibiotics have been used. Furthermore, it is questionable whether or not they are actually quantitative.

Similarly, there are both advantages and disadvantages of molecular methods. Advantages include their speed, increased sensitivity and the fact that they can be done on inadequately stored specimens. In addition, databases and phylogenetic trees can be readily made and automation is possible. Disadvantages are that significant costs

\begin{tabular}{ll}
\hline KARGER & ( ) 2005 S. Karger AG, Basel \\
Fax +4161306 1234 $34-7571 / 05 / 0147-0020 \$ 22.00 / 0$ \\
$\begin{array}{l}\text { E-Mail karger@karger.ch } \\
\text { www.karger.com }\end{array}$ & $\begin{array}{l}\text { Accessible online at: } \\
\text { www.karger.com/mpp }\end{array}$
\end{tabular}


are involved (in reagents, apparatus, personnel), no bacteria are isolated for further studies, specimen adequacy cannot be determined, there is a risk of contamination especially if done by untrained staff (non-microbiologists), confirmatory tests are often necessary and the methods are not yet widely accepted for medicolegal testing.

\section{Diagnostic Methods}

With regard to diagnosis, one of the first considerations is whether the method must be rapid or not. Although speed is often important, it is sometimes appropriate and in the interest of both the patient and the economics of the process for a result to be ready in hours or days rather than minutes or hours. Slower and often cheaper procedures are more appropriate when an immediate result is not deemed necessary. A rapid result is required if therapy or management can be instigated only after the result is known. However, empirical treatment with a broad-spectrum antibiotic may be used to buy time.

Without doubt, the sooner a result is known the better for life-threatening infections such as meningitis or septicaemia. Blood culture methodology has advanced greatly, but results still take time. Similarly many paediatric infections require an early diagnosis. From a different point of view, diagnosis of sexually transmitted infections can benefit from a rapid diagnosis, so that patients can be treated before they leave the clinic.

The early generation of rapid tests was based on detection of antigens in specimens, utilising antigen capture in enzyme immunoassay, or antigen detection by immunofluorescence. The more recent tests involve nucleic acid methods, relying on detection of specific genes by an amplification method such as PCR, including the much more quantitative real-time PCR, or the use of gene probes. A special case where molecular methods are making huge inroads is for the rapid diagnosis of tuberculosis and other mycobacterial infections. Mycobacterium tuberculosis and related species are extremely slow growers in laboratory media and take several weeks to culture. Proper diagnosis is needed both to institute appropriate therapy and also to isolate patients to prevent transmission of disease.

A comparison of traditional culture with modern, rapid tests is illustrated in table 1. Here the diagnosis of Chlamydia trachomatis infection is examined [1]. The specificity of all methods is fairly high, but the sensitivity for the immunoassays is sometimes poor.

Molecular Techniques in Bacteriology
Table 1. Sensitivity and specificity of $C$. trachomatis testing

\begin{tabular}{lll}
\hline Method & Sensitivity, \% & Specificity, \% \\
\hline Culture & $70-90$ & 100 \\
Nucleic acid amplification & $90-100$ & $97-100$ \\
DNA probe & $67-96$ & $96-100$ \\
Immunofluorescence & $70-100$ & $>95$ \\
Enzyme immunoassay & $43-92$ & $92-100$ \\
\hline
\end{tabular}

Modified from Medscape Molecular Medicine [1].

For routine diagnostic procedures, a combination of both approaches, traditional and molecular, can probably be employed for optimal information. To illustrate this combined approach, the following is an example of a typical investigation of a stool specimen for a suspected infection caused by an enterohaemorrhagic Escherichia coli, an easily cultured bacterium. Following clinical symptoms of bloody diarrhoea and haemolytic uraemic syndrome/thrombocytopaenia purpura, the stool specimen is cultured on MacConkey's agar containing 1\% Dsorbitol. Non-sorbitol-fermenting colonies are confirmed as E. coli $\mathrm{O} 157$ by latex agglutination tests. In an accompanying epidemiological investigation, enrichment might be done from food, water or faeces by immunomagnetic beads. The stx gene, and possibly LEE or other virulence genes could be detected with DNA probes. Finally pulsedfield gel electrophoresis might be used to compare isolates.

\section{Identification, Typing and Fingerprinting - Epidemiological or Taxonomic Tools}

The use of molecular methods for bacterial identification is most useful for bacteria that are either difficult to grow or are easy to grow yet are biochemically unreactive.

Examples of the latter are members of the genus Actinomyces. Val Hall et al. [2, 3] have made major improvements to the identification of these species using a technique based on amplified $16 \mathrm{~S}$ ribosomal DNA restriction analysis.

Investigation of slow or non-cultivable bacteria has usually been done using traditional serology. Now such organisms can be investigated by probe or PCR detection, and new associations between symptoms and organism can be drawn. An important example of such an investi-

Med Princ Pract 2005;14(suppl 1):20-26 


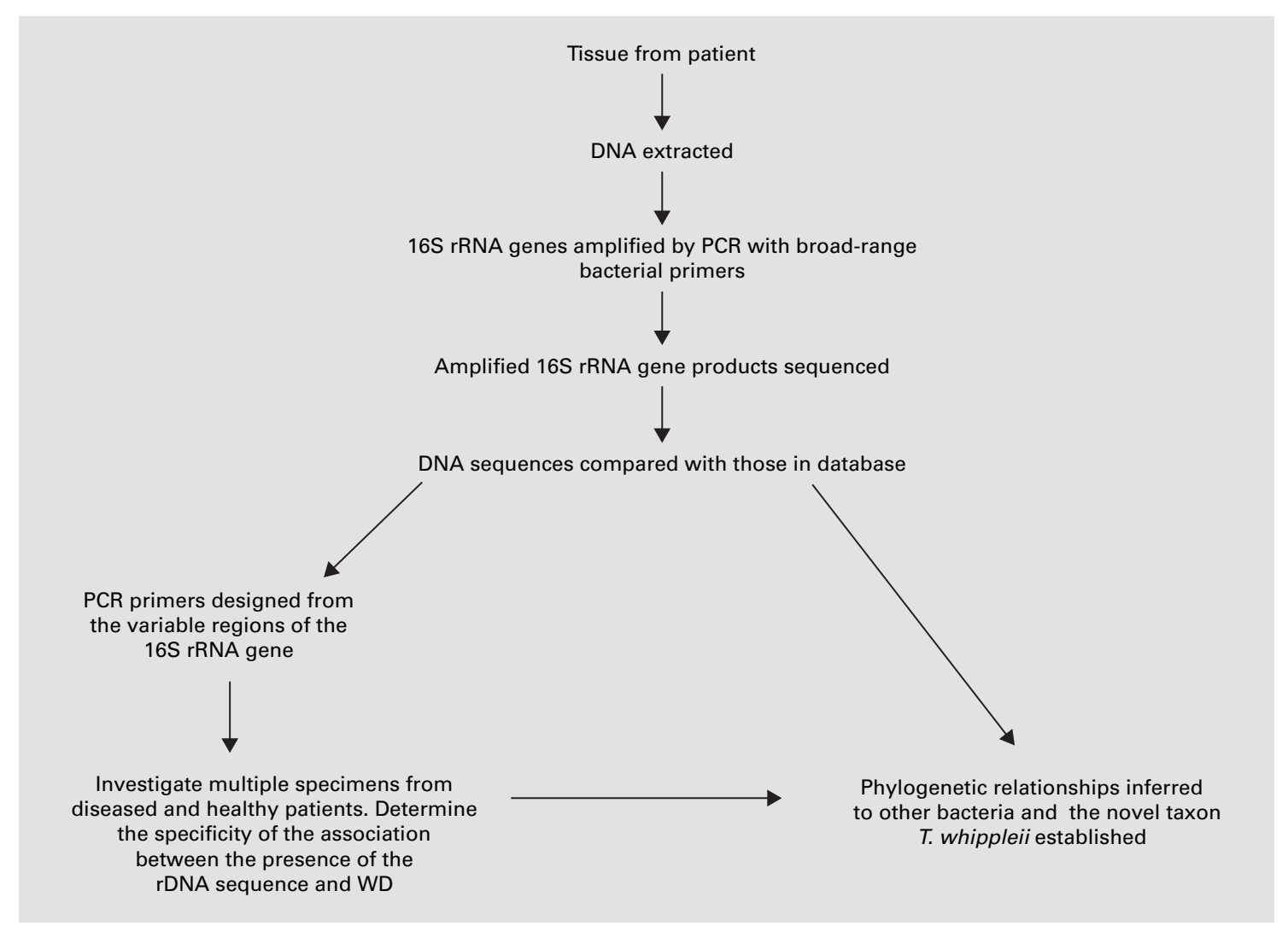

Fig. 1. The investigation of Whipple's disease (WD; modified from Fredricks and Relman [6]).

gation is that of Whipple's disease. This disease is a rare infection of the small intestine causing malabsorption. It was thought to be a bacterial disease since its discovery in 1907, since bacilli were seen in affected areas and it responded later to antibiotic treatment. The final proof that it was caused by the bacterium Tropheryma whippelii was done entirely by a sequence-based approach $[4,5]$. The approach is summarised diagrammatically in figure 1, modified from Fredricks and Relman [6].

\section{Studying Pathogenesis}

The aetiology of an infectious disease has traditionally been investigated through the establishment of Koch's postulates. However, for many reasons, not least those of ethics, inability to culture an organism and the preponderance of opportunist infections arising from the endogenous microbiota, they have been impossible to fulfil. As a result of this, molecular Koch's postulates have been created [7], which are listed in table 2.
Table 2. Establishment that a bacterium is the cause of a disease and identification of virulence factors by fulfilment of 'molecular Koch's postulates'

1 Identify a gene coding for a virulence determinant that is associated with all bacteria that cause the disease and is not present in avirulent strains

2 Inactivation of the gene coding for the virulence factor should substantially decrease pathogenicity

3 Replacement of the mutated gene with the normal wild-type gene should restore pathogenicity fully

4 The gene should be expressed during the infection and disease process

5 A protective immune response should be produced to the gene product

\section{Patient Management}

Monitoring the progression of disease is done traditionally by clinical monitoring, culture and measuring a serological response. However, with the advent of mo- 
lecular methods, such traditional approaches may be superseded. For example, detection of mediators of disease is traditionally accomplished by clinical measurements, from simple temperature changes to acute physiology scores. Measurement of acute-phase proteins such as Creactive protein has long been used [8]. Other mediators are proinflammatory cytokines such as tumour necrosis factor alpha (TNF- $\alpha$ ), interleukin (IL)-1, IL-2, IL-6, IL-8 and IFN, which are usually detected by immunoassays or bioassays. However, molecular approaches are now possible, for example by detecting specific messenger RNAs by reverse transcriptase PCR $[9,10]$.

Another method, which is 'molecular' but not nucleic acid-based, involves the detection of the prime mediator of inflammation: endotoxin [bacterial lipopolysaccharide (LPS)]. Traditionally, endotoxin has been detected by measuring its pyrogenicity in the rabbit fever model. More recently, this has been largely superseded by the Limulus amoebocyte lysate assay, which is an assay based on the exquisite sensitivity of the lysed amoebocytes from the horseshoe crab L. polyphemus. Exposure to endotoxin results in gelation of the lysate. Either the original clotting (gelation) assay or the more specific colourimetric version can be used. Despite years of experience, it is not routinely used in diagnosis, mainly because of the difficulty in use, especially its lack of reproducibility probably due to the relatively short half-life of endotoxin in plasma. Downstream mediators such as IL-6 have a much greater half-life. Also the extreme sensitivity of the test makes it very prone to contamination, which can cause false positives.

An indirect method for endotoxin determinations has been used a great deal in our laboratory and elsewhere. In this assay, EndoCAb ${ }^{\mathrm{TM}}$, antibodies to endotoxin core are measured and their levels are inversely related to endotoxin level over time. It is also a prognostic indicator, where high levels are considered protective for endotoxin-related problems, as discussed below. A kit is available commercially (Hycult Biotechnology BV, The Netherlands). The coating (detecting) antigens in this ELISA are incomplete for core-lipid A structures from R-mutants of LPSs: from E. coli, Salmonella minnesota, Klebsiella pneumoniae and Pseudomonas aeruginosa combined in equimolar proportions and complexed with polymyxin. This assay detects antibodies that cross-react with the common epitopes expressed by these incomplete core LPSs in blood donors and patients. Early investigations employing this assay were reviewed by Barclay in 1995 [11], and since then the kit has been used for many different investigations [12-14].

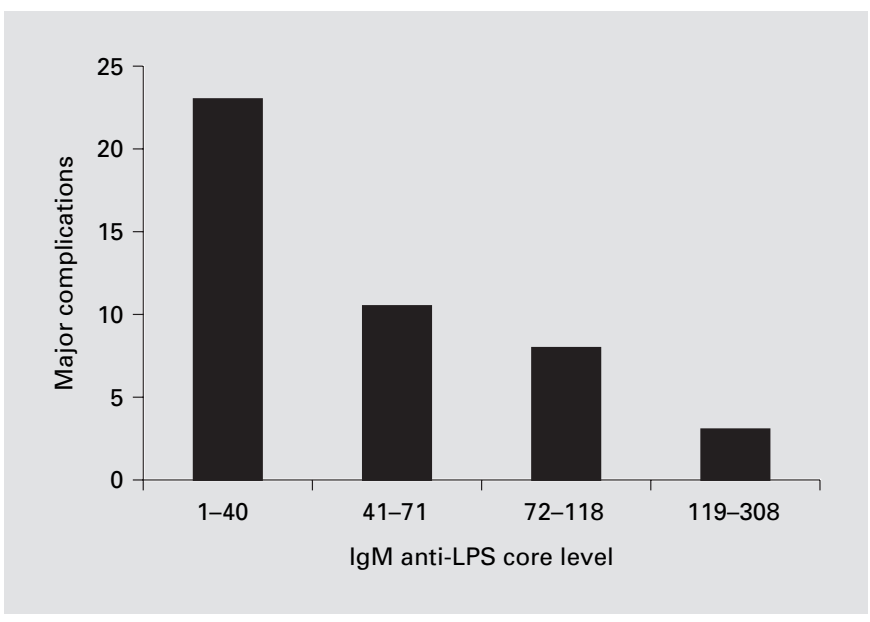

Fig. 2. High pre-operative IgM levels protect against endotoxaemia following cardiac surgery. This figure shows that pre-operative low serum anti-endotoxin core antibody (EndoCAb) levels are a predictor of adverse outcome following cardiac surgery. Major complication is defined as either in-hospital death or postoperative length of stay greater than 10 days. Antibody levels are in median units for the EndoCA ELISA (modified from Bennett-Guerrero et al. [17]).

\section{Investigating Susceptibility to Infectious Diseases}

Disease susceptibility is often associated with the genotype of the individual. Polymorphisms in several different genes have been associated with differential susceptibility to infections and the magnitude of symptoms. Polymorphisms in cytokine genes such as TNF- $\alpha$ and Toll-like receptors are well-cited examples. Recently, however, doubt has been cast on how important these polymorphisms are. Bayley et al. [15] have questioned the relevance of TNF polymorphisms and suggested that the evidence indicates that they are important only in malaria. Similarly, we have questioned the significance of Toll-like receptor 4 polymorphisms [16].

As mentioned above, deficiencies in antibodies to endotoxin, as measured by the EndoCAb method, indicate possible susceptibility to endotoxin-related problems. Conversely, high levels of antibodies are considered to be protective. Studies show that if patients have high preoperative levels of antibodies to the LPS core, they have a much better chance of not developing endotoxin-related complications than patients who have low levels $[17,18]$. Figure 2 summarises the results of the study conducted on cardiac surgery patients [17] demonstrating that high pre-operative levels of antibodies to the LPS core afford protection, and these high levels should be the target lev- 
Table 3. Comparison of culture with gene probe detection kit for MRSA in blood cultures

\begin{tabular}{llc}
\hline \multirow{2}{*}{ Test } & \multicolumn{2}{c}{ Comparison with $m e c A / f e m B$ PCR } \\
\cline { 2 - 3 } & sensitivity, \% & specificity, \% \\
\hline EVIGENE & 100 & 99.5 \\
Culture & 88.2 & 99.5 \\
\hline
\end{tabular}

Modified from Levi and Towner [22].

els for any future vaccine trials. We have also shown consumption of anti-Bacteroides LPS antibodies during episodes of sepsis, suggesting that the Gram-negative anaerobes, as well as other gastro-intestinal Gram-negative bacteria may be translocated into the peripheral circulation during sepsis [19].

We have recently developed and tested preclinically a vaccine designed to boost natural levels of anti-LPS core antibodies [20,21]. The vaccine contains a set of R-LPSs in liposomes. It is non-pyrogenic, gives good seroconversion and is cross-reactive with smooth LPSs in mice and rabbits, and is protective in mouse models. New work is concentrating on core oligosaccharide-protein conjugates as vaccines and results are similar to the liposomal vaccines.

\section{Detecting Resistance to Antimicrobial Agents}

Several molecular methods have been developed to detect resistance to antimicrobial agents by detecting resistance genes. These methods certainly have a role in investigating the epidemiology of resistance genes, but when we have disk testing for cultures on primary isolation plates, MIC testing on pure cultures by broth or agar dilutions, or E-tests, are they really necessary?

Generally speaking, the answer is no, although there are a few notable exceptions which will be described here.

(a) The first example is for rapid detection of methicillin-resistant Staphylococcus aureus (MRSA) in blood cultures. This technique is based on probes for resistance genes and an example of this has recently been reported by Levi and Towner [22], who employed the EVIGENE ${ }^{\text {TM }}$ MRSA detection kit (Statens Serum Institute, Copenhagen, Denmark). The method involves mixing samples with sterile water to lyse red blood cells. This is then incubated in broth at $37^{\circ} \mathrm{C}$ for $3 \mathrm{~h}$. After centrifugation, the pellet is tested with the EVIGENE MRSA detection kit.
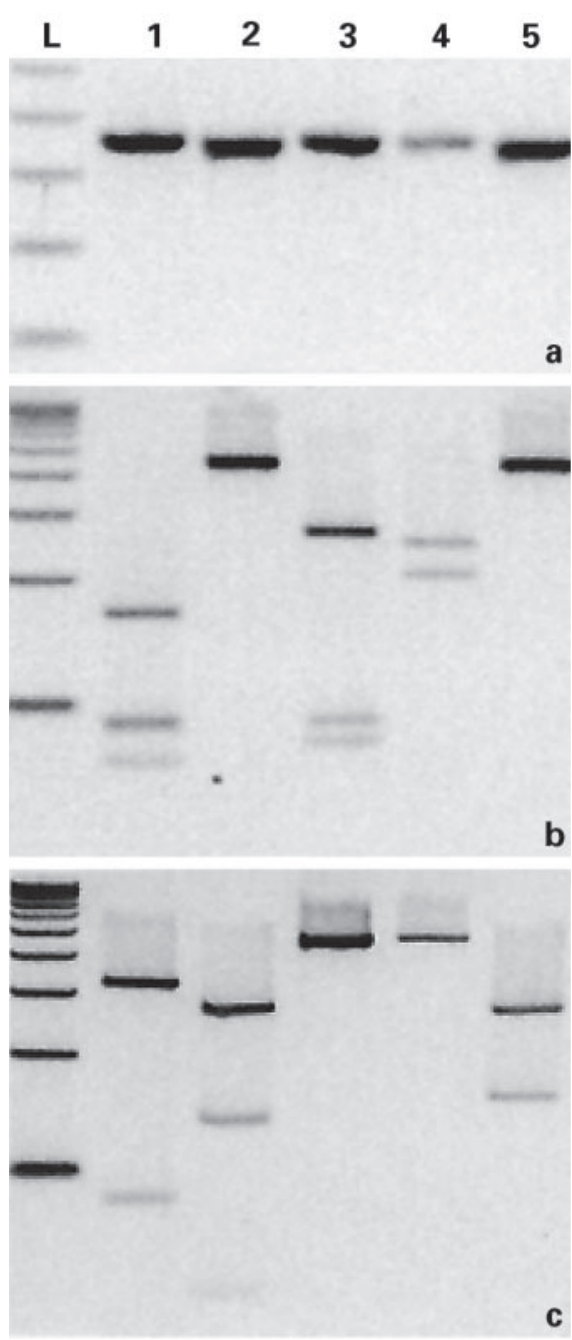

Fig. 3. PCR-RFLP analyses for identification and characterization of nim resistance genes of Bacteroides spp. PCR products (a) and RFLP profiles for HpaII (b) and TaqI (c) for genes nimA to $\operatorname{nim} E$. L = 100-bp ladder. From Stubbs et al. [24], with permission from A.S.M. (Journal of Clinical Microbiology).

The pellet is lysed by treatment with enzyme and heat, the probes mecA, nuc, and 16S rRNA are added in microwell strips and the results read colourimetrically in less than $3.5 \mathrm{~h}$. They compared the efficacy of EVIGENE and conventional culture with $m e c A / f e m B$ PCR for detection of MRSA in 200 blood cultures, and the results compared well with culture (table 3 ). The time to results after positive blood culture was $7 \mathrm{~h}$ for EVIGENE, compared to $1+$ day for conventional culture. 


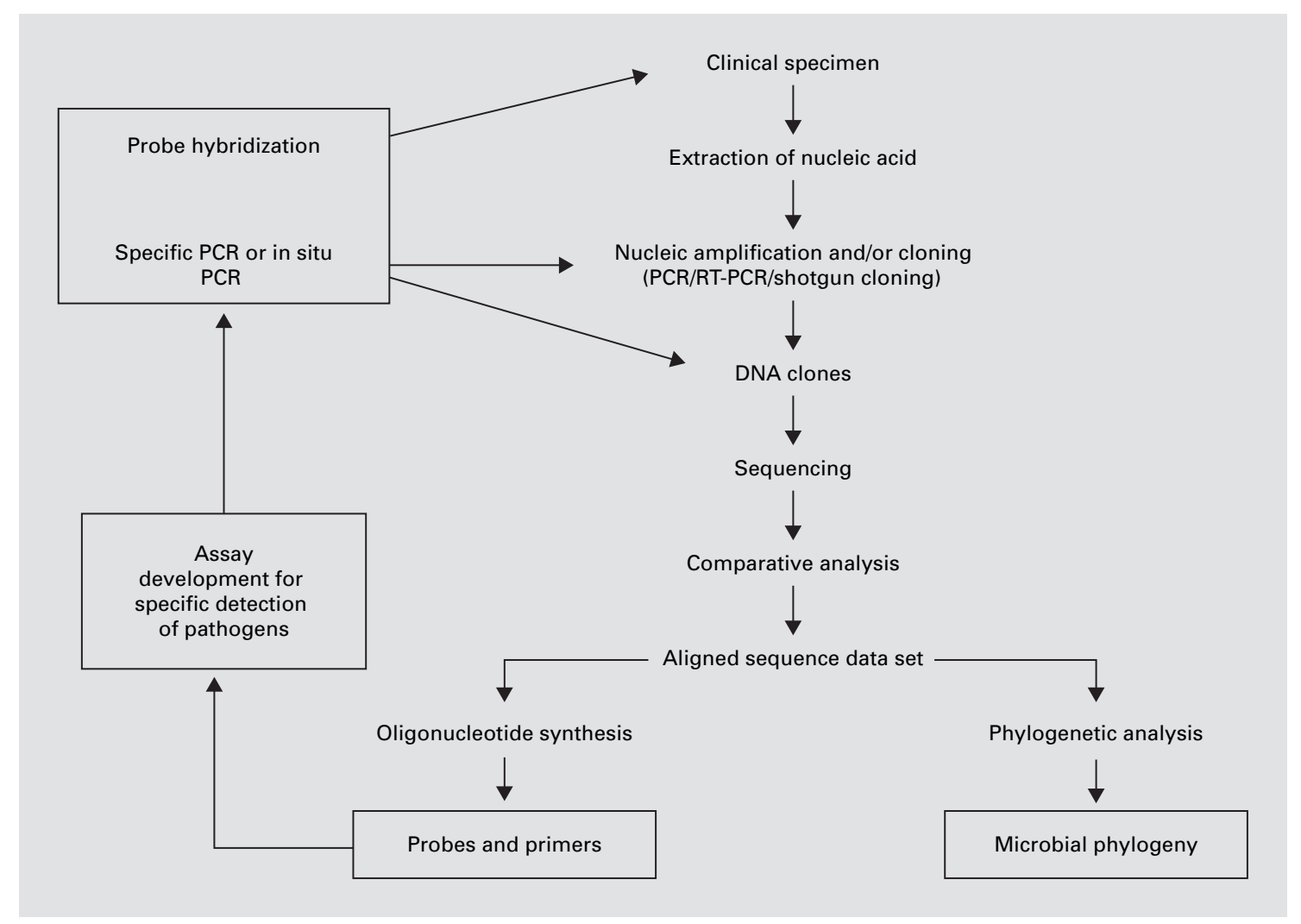

Fig. 4. Is this the way for the future? Simplified from Fredricks and Relman [6].

(b) Another example is detecting resistance to 5-nitroimidazole antibiotics (e.g. metronidazole) in anaerobic bacteria [23]. Detection of antibiotic resistance in anaerobes requires a good anaerobic technique, which is sometimes difficult to achieve. Molecular methods can be used to detect genes that code for resistance factors. In the $\mathrm{Bac}$ teroides fragilis group of species 5 nim genes (A, B, C, D and $\mathrm{E}$ ) have been identified that confer resistance to 5-nitroimidazole antibiotics. Figure 3 shows the PCR-RFLP analyses of nim resistance genes of Bacteroides spp.

In summary, the detection of resistance to antimicrobial agents by molecular approaches permits very rapid detection and indicates specific resistance mechanisms, but these methods are not quantitative. MICs need to be determined separately by traditional approaches.

Figure 4 is an attempt to illustrate what the future may bring. Some laboratories are already pursuing such a scheme, although at present they are doing this in parallel with traditional methods. Innovation is to be encouraged in new technologies, but these must be thoroughly tested before introduction into the routine laboratory. Good communication is absolutely necessary between laboratory scientist and physician, and finally experience is paramount.

\section{Conclusions}

Molecular methods are advancing rapidly and are gaining an important place in all aspects of diagnosis and management of bacterial infectious diseases. However, traditional methods are still needed, and there is still much to be learned about them. The training of staff should include both methodologies. 


\section{References}

1 Molecular Diagnosis of Common STDs. Medscape Molecular Medicine, 2003, vol 5.

-2 Hall V, O’Neill GL, Magee JT, Duerden BI: Development of amplified 16S ribosomal DNA restriction analysis for identification of Actinomyces species and comparison with pyrolysis-mass spectrometry and conventional biochemical tests. J Clin Microbiol 1999;37: 2255-2261.

- 3 Hall V, Talbot PR, Stubbs SL, Duerden BI: Identification of clinical isolates of Actinomyces species by amplified $16 \mathrm{~S}$ ribosomal DNA restriction analysis. J Clin Microbiol 2001;39: 3555-3562.

4 Relman DA, Schmidt TM, MacDermott RP, Falkow S: Identification of the uncultured bacillus of Whipple's disease. N Engl J Med 1992; 327:293-301.

${ }_{5}$ Wilson KH, Blitchington R, Frothingham R, Wilson JA: Phylogeny of the Whipple's-disease-associated bacterium. Lancet 1991;338: 474-475.

6 Fredricks DN, Relman DA: Sequence-based identification of microbial pathogens: A reconsideration of Koch's postulates. Clin Microbiol Rev 1996;9:18-23.

7 Falkow S: Molecular Koch's postulates applied to bacterial pathogenicity - A personal recollection 15 years later. Nat Rev Microbiol 2004; 2:67-72.

8 Almirall J, Bolibar I, Toran P, Pera G, Boquet X, Balanzo X, Sauca G: Community-Acquired Pneumonia Maresme Study Group. Contribution of C-reactive protein to the diagnosis and assessment of severity of community-acquired pneumonia. Chest 2004;125:1335-1342.

-9 Gerard HC, Wang Z, Whittum-Hudson JA, ElGabalawy H, Goldbach-Mansky R, Bardin T, Schumacher HR, Hudson AP: Cytokine and chemokine mRNA produced in synovial tissue chronically infected with Chlamydia trachomatis and C. pneumoniae. J Rheumatol 2002; 29:1827-1835.
10 Ulett GC, Ketheesan N, Hirst RG: Cytokine gene expression in innately susceptible BALB/ c mice and relatively resistant C57BL/6 mice during infection with virulent Burkholderia pseudomallei. Infect Immun 2000;68:20342042.

11 Barclay GR: Endogenous endotoxin-core antibody (EndoCAb) as a marker of endotoxin exposure and a prognostic indicator: A review; in Levin J, Alving CR, Munford RD, Redl H (eds): Bacterial Endotoxins: Lipopolysaccharides from Genes to Therapy. Proceedings of the 3rd Conference of the International Endotoxin Society (August 1994, Helsinki, Finland). New York, Wiley, 1995.

12 Ide M, Jagdev D, Coward PY, Crook M, Barclay GR, Wilson RF: The short-term effects of treatment of chronic periodontitis on circulating levels of endotoxin, C-reactive protein, tumor necrosis factor-alpha, and interleukin-6. J Periodontol 2004;75:420-428.

13 Willetts IE, Kite P, Barclay GR, Banks RE, Rumley A, Allgar V, Stringer MD: Endotoxin, cytokines and lipid peroxides in children with intussusception. Br J Surg 2001;88:878-83.

14 Clements WD, Erwin P, McCaigue MD, Halliday I, Barclay GR, Rowlands BJ: Conclusive evidence of endotoxaemia in biliary obstruction. Gut 1998;42:293-299.

$\checkmark 15$ Bayley JP, Ottenhoff THM, Verweij CL: Is there a future for TNF promoter polymorphisms? Genes Immun 2004;5:315-329.

16 Erridge C, Stewart J, Poxton IR: Monocytes heterozygous for the Asp299Gly and Thr399Ile mutations in the Toll-like receptor 4 gene show no deficit in LPS signalling. J Exp Med 2003; 197:1787-1791.
17 Bennett-Guerrero E, Ayuso L, Hamilton-Davies $C$, White WD, Barclay GR, Smith PK, King SA, Muhlbaier LH, Newman MF, Mythen MG: Relationship of preoperative antiendotoxin core antibodies and adverse outcomes following cardiac surgery. JAMA 1997;277: 646-650.

18 Bennett-Guerrero E, Panah MH, Barclay GR, Bodian CA, Winfree WJ, Andres LA, Reich DL, Mythen MG: Decreased endotoxin immunity is associated with greater mortality and/or prolonged hospitalization after surgery. Anesthesiology 2001;94:992-998.

19 Bennett-Guerrero E, Barclay GR, Youssef ME, Hossain S, Vela-Cantos F, Andres LA, Poxton IR: Exposure to Bacteroides fragilis endotoxin during cardiac surgery. Anesth Analg 2000;90: 819-823.

20 Bennett-Guerrero E, McIntosh TJ, Barclay GR, Snyder S, Gibbs RJ, Mythen MG, Poxton IR: Preparation and preclinical evaluation of a novel liposomal complete-core lipopolysaccharide vaccine. Infect Immun 2000;68:62026208.

21 Erridge C, Stewart J, Bennett-Guerrero E, McIntosh TJ, Poxton IR: The biological activity of a liposomal complete core lipopolysaccharide vaccine. J Endotoxin Res 2002;8:39-46.

22 Levi K, Towner KJ: Detection of methicillinresistant Staphylococcus aureus (MRSA) in blood with the EVIGENE MRSA detection kit. J Clin Microbiol 2003;41:3890-3892.

23 Rotimi, VO, Khoursheed M, Brazier JS, Jamal WY: Bacteroides species highly resistant to metronidazole: An emerging problem. Clin Microbiol Infect 1999;5:166-169.

24 Stubbs SL, Brazier JS, Talbot PR, Duerden BI: PCR-restriction fragment length polymorphism analysis for identification of Bacteroides spp and characterization of nitroimidazole resistance genes. J Clin Microbiol 2000;38: 3209-3213. 